\title{
The G-Protein-Coupled Serotonin Receptor SER-1 Regulates Egg Laying and Male Mating Behaviors in Caenorhabditis elegans
}

\author{
Lucinda Carnell, Julie Illi, Swung Woo Hong, and Steven L. McIntire \\ Ernest Gallo Clinic and Research Center, Department of Neurology, Programs in Neuroscience and Biomedical Science, University of California, San \\ Francisco, Emeryville, California 94608
}

\begin{abstract}
Serotonin (5-HT) is a neuromodulator that regulates many aspects of animal behavior, including mood, aggression, sex drive, and sleep. In vertebrates, most of the behavioral effects of 5-HT appear to be mediated by G-protein-coupled receptors (GPCRs). Here, we show that SER-1 is the 5-HT GPCR responsible for the stimulatory effects of exogenous 5-HT in two sexually dimorphic behaviors of Caenorhabditis elegans, egg laying and male ventral tail curling. Loss of ser-1 function leads to decreased egg laying in hermaphrodites and defects in the turning step of mating behavior in males. ser- 1 is expressed in muscles that are postsynaptic to serotonergic neurons and are known to be required for these behaviors. Analysis of the ser-1 mutant also reveals an inhibitory effect of 5-HT on egg laying that is normally masked by SER-1-dependent stimulation. This inhibition of egg laying requires MOD-1, a 5-HT-gated chloride channel. Loss of mod-1 function in males also produces defects in ventral tail curling and enhances the turning defects in ser-1 mutant males. Sustained elevations in 5-HT levels result in behavioral adaptation to both the stimulatory and inhibitory actions of the neurotransmitter, indicating that both SER-1 and MOD-1 signaling can be modulated. Removal of wild-type animals from high levels of exogenous 5-HT produces a SER-1-dependent withdrawal response in which egg laying is significantly decreased. These studies provide insight into the role of 5-HT in behavior and the regulation of $5-\mathrm{HT}_{2}$ receptor function.
\end{abstract}

Key words: C. elegans; serotonin; GPCR; SER-1; egg laying; male mating; MOD-1

\section{Introduction}

The neurotransmitter 5-hydroxytryptamine (5-HT) is widely used in the nervous systems of both invertebrate and vertebrate organisms and modulates many aspects of behavior. In Caenorhabditis elegans, 5-HT regulates locomotion, egg laying, pharyngeal pumping, and male mating behaviors (Loer and Kenyon, 1993; Waggoner et al., 1998; Duerr et al., 1999; Nurrish et al., 1999; Sawin et al., 2000; Sze et al., 2000). Application of exogenous 5-HT to wild-type animals inhibits locomotion and stimulates egg laying, pharyngeal pumping, and the ventral tail curling that occurs during male mating (Horvitz et al., 1982; Loer and Kenyon, 1993; Schafer and Kenyon, 1995; Nurrish et al., 1999). C. elegans adapts to the effects of exogenous 5-HT on egg laying and locomotion after long-term exposure to the drug (Schafer and Kenyon, 1995). Searches for G-protein-coupled receptors (GPCRs) that could mediate these effects of 5-HT in C. elegans

Received Nov. 29, 2004; revised 0ct. 3, 2005; accepted 0ct. 3, 2005.

This work was supported by funds provided by the State of California for medical research on alcohol and substance abuse through the University of California, San Francisco. Worm strains used were provided by the $C$ elegans Genetics Center, which is funded by a grant from the National Institutes of Health National Center for Research Support, and the C. elegans Gene Knockout Consortium. We thank Jill Bettinger and members of the McIntire laboratory for helpful discussions and critical reading of this manuscript.

Correspondence should be addressed to Steven L. McIntire, Ernest Gallo Clinic and Research Center, Department of Neurology, Programs in Neuroscience and Biomedical Science, University of California, San Francisco, 5858 Horton Street, Suite 200, Emeryville, CA 94608. E-mail: slm@itsa.ucsf.edu.

DOI:10.1523/JNEUROSCI.3399-05.2005

Copyright $\odot 2005$ Society for Neuroscience $\quad$ 0270-6474/05/2510671-11\$15.00/0 have identified three candidate genes [ser-1, ser-4 (formerly 5-HT-Ce or cer-1), and ser-7b] encoding receptors shown to bind 5-HT in vitro (Olde and McCombie, 1997; Hamdan et al., 1999; Hobson et al., 2003). In addition to the candidate GPCRs, a 5-HT-gated chloride channel, MOD-1, has been identified in $C$. elegans and shown to be required for the enhanced slowing response of food-deprived animals after encountering bacteria (Ranganathan et al., 2000; Sawin et al., 2000).

The neuromuscular circuits that are likely to mediate the effects of 5-HT on egg laying and ventral tail curling have been studied extensively. In the C. elegans hermaphrodite, egg laying is mediated by 16 vulval and uterine muscles that receive neuronal input from two classes of motorneurons, the ventral-type C (VC) and the hermaphrodite-specific neurons (HSNs), both of which contain 5-HT (Desai and Horvitz, 1989; Duerr et al., 1999; Sze et al., 2000). The male-specific CP motorneurons are immunoreactive for 5-HT and innervate the male-specific diagonal muscles that are important for proper turning in males (Loer and Kenyon, 1993).

Here, we determined that SER-1, a 5-HT GPCR, is the receptor that mediates the stimulatory effects of 5-HT on egg laying and ventral tail curling. Interestingly, the SER-1 receptor shows high homology to the vertebrate $5-\mathrm{HT}_{2}$ type receptors (Hamdan et al., 1999) that influence many aspects of mammalian behavior, such as feeding and mood, and are targets of a variety of psychoactive medications, including antidepressants, anxiolytics, and 
atypical antipsychotic drugs (for review, see Roth et al., 1998; Giorgetti and Tecott, 2004). Our additional analysis of the responses of the ser-1 mutant to exogenous 5-HT also reveals a previously undescribed inhibitory effect of 5-HT on egg laying not observed in wild-type animals. This inhibitory response is dependent on the 5-HT-gated chloride channel, MOD-1. Longer exposures to 5-HT can diminish the 5-HT-dependent effects on egg laying and lead to a dependence on 5-HT for egg laying. This dependence produces a withdrawal response that requires the SER-1 receptor. Together, these observations suggest that C. elegans is a good model for studying acute and adaptive responses to serotonin.

\section{Materials and Methods}

Strains. C. elegans were maintained as described previously (Brenner, 1974). The wild-type strain used was Bristol N2. Mutant strains were obtained from the C. elegans Genetics Center (Minneapolis, MN). ser1(ok345) and mod-1(ok103) were generated by the C. elegans Gene Knockout Consortium (Oklahoma City, OK). The ser-1 strain used was DA1814 (outcrossed 10 times), and the mod-1 strain used was MT9668 (outcrossed six times). Mutants used were as follows: ser-1(ok345), mod1(ok103), unc-13(e1091), tph-1 (mg280), egl-1(n487), unc-42(e270), and the deficiency strain TY404 (+/szT1[lon-2(e678)]; lin-15(n765)Df1/ szT1). The double mutants ser-1(ok345);mod-1(ok103), ser-1(ok345);egl1(n487), and ser-1(ok345);unc-42(e270) were constructed using standard genetic techniques.

RNA-mediated interference. RNA-mediated interference (RNAi) experiments were performed as described previously (Kamath and Ahringer, 2003) using wild-type N2 animals. Fourth larval (L4) stage hermaphrodites and their progeny were grown on nematode growth media (NGM) agar plates containing $25 \mu \mathrm{g} / \mathrm{ml}$ carbenicillin and $1 \mathrm{~mm}$ isopropyl- $\beta$-D-thiogalactopyranoside and seeded with HT115(DE3) bacteria containing either the ser-1 (F59C12.2) RNAi vector or an empty vector, which served as a control (gift from Dr. J. Ahringer, Wellcome Institute, Cambridge, UK).

Behavioral assays. The age-matched adults used in all of the egg-laying assays were obtained by picking L4 stage hermaphrodites $24-30 \mathrm{~h}$ before each assay and culturing on food at $20^{\circ} \mathrm{C}$.

For egg-laying assays performed in liquid, age-matched adults were placed into $50 \mu \mathrm{l}$ of M9 buffer $\left[\mathrm{KH}_{2} \mathrm{PO}_{4}(3 \mathrm{~g} / \mathrm{L}), \mathrm{Na}_{2} \mathrm{HPO}_{4}(6 \mathrm{~g} / \mathrm{L}), \mathrm{NaCl}\right.$ $(5 \mathrm{~g} / \mathrm{L})$, and $10 \mathrm{mM} \mathrm{MgSO}_{4}$ ] and the indicated compounds. The number of eggs laid in each well was counted after $90 \mathrm{~min}$ (except for assays using $\alpha$-methyl-5-HT-treated animals, in which the number of eggs laid was counted after $60 \mathrm{~min}$ ). 5-HT (Sigma, St. Louis, MO) was used at $12.5 \mathrm{~mm}$ in M9 buffer. Levamisole, nicotine, and oxotremorine M (Sigma) were used at $50 \mu \mathrm{M}, 0.5 \%$, and $20 \mathrm{~mm}$, respectively, all in M9 buffer. $\alpha$-Methyl5-HT (Sigma) was used at $125 \mu \mathrm{M}$ in water.

For acute egg-laying assays performed on plates, NGM agar plates containing 5 -HT were prepared $1-2 \mathrm{~d}$ before the experiment by adding 5-HT (final concentration, $7.5 \mathrm{~mm}$ ) to the liquid NGM agar before pouring. To contain the animals, four copper rings ( $13 \mathrm{~mm}$ in diameter) were embedded into the NGM plates, and a single drop of concentrated Escherichia coli strain OP50 bacteria was placed into the center of each ring as a food source and allowed to dry. Ten animals were placed inside each ring. The number of eggs laid after $60 \mathrm{~min}$ was counted.

For adaptation assays, NGM agar plates containing 5-HT were prepared as described above. Age-matched adults were placed onto NGM plates containing $7.5 \mathrm{~mm} 5-\mathrm{HT}$ for $4-5 \mathrm{~h}$. Control animals were placed onto NGM plates containing $0 \mathrm{~mm} 5$-HT for the same length of time. Ten animals were then transferred to NGM plates containing either $0 \mathrm{~mm}$ 5-HT or 7.5 mM 5-HT and assayed in the same manner as in the acute assay. The number of eggs laid after $60 \mathrm{~min}$ was counted.

To determine the number of eggs in utero, age-matched adults were placed singly into microtiter wells containing $50 \mu \mathrm{l}$ of $5 \%$ sodium hypochlorite, which dissolves the animals but leaves the eggs intact. After the animals dissolved (5-10 min), the number of eggs was counted for each animal.

In the tail-curling assay, age-matched males were obtained by picking
L4 stage males $16-20 \mathrm{~h}$ before experiments were performed and culturing on food at $20^{\circ} \mathrm{C}$. Five males were placed into $50 \mu \mathrm{l}$ of $20 \mathrm{~mm} 5$-HT in M9 buffer (Loer and Kenyon, 1993). After 15 min, the number of males with curled tails was counted.

For male turning behavior, age-matched males were obtained by picking L4 males $16-20 \mathrm{~h}$ before experiments were performed and culturing on food at $20^{\circ} \mathrm{C}$. A single male and $20 u n c-13(e 1091)$ L4 hermaphrodites were placed on a $6 \mathrm{~cm}$ NGM agar plate seeded with a small drop of OP50 bacteria. unc-13 hermaphrodites were used for the matings because they move poorly, which makes it easy for males to locate them. L4 hermaphrodites, which lack a vulval opening, were used to allow individual males to perform a large number of turns, because turning behavior persists until the male locates the vulva. The number of turns was counted for 2 min after initiation of the first turning event. Turns were scored blind as to genotype as "good," "sloppy," and "missed" as initially described by Loer and Kenyon (1993).

For mating efficiency assays, single unc-13 L4 hermaphrodites were placed onto an agar plate seeded with OP-50 E. coli bacteria with a single L4 mutant male. The number of cross progeny was determined by counting the number of non-Unc animals that were produced from the mating.

Molecular biology. The Pser-1::gfp transgene construct was made according to the Hobert (2002) method of fusing the ser-1 promoter PCR product to a PCR product containing the $g f p$ open reading frame. The primers used to generate the ser- 1 promoter product were: $5^{\prime}$, CAGGACGAGCTGTTGA; 3', AGTGCACCTGCAGGCATGCAAGCTGAGCGCTGTGTGAGAAGAGTTC. This PCR product contains $8.1 \mathrm{kB}$ of the ser-1 promoter and $9 \mathrm{bp}$ of the first exon. Germline transformation was performed as described previously (Mello and Fire, 1995). The Pser-1::gfp was injected into N2 wild-type animals at a concentration of $50 \mu \mathrm{g} / \mathrm{ml}$ together with $50 \mu \mathrm{g} / \mathrm{ml}$ pBluescript vector, which served as carrier DNA. Stable lines containing extrachromosomal arrays were isolated. Three stable lines were examined and showed similar patterns of $g f p$ expression. One line was chosen for additional analysis, egEx21[Pser-1::gfp; pBS].

The extrachromosomal arrays carrying the ser-1 rescuing transgene construct, egEx18[ser-1(+);Pofm-1::gfp], egEx19[ser-1(+);Pofm-1::gfp], and egEx20[ser-1(+);Pofm-1::gfp] contain a $15 \mathrm{kB}$ ser-1 PCR product from genomic DNA that includes $7 \mathrm{kB}$ upstream of the ser- 1 openreading frame and $884 \mathrm{bp}$ of the $3^{\prime}$-UTR. The extrachromosomal array that did not rescue the ser-1 phenotype, egEx33[ser-1(+);Pofm-1::gfp], contains an $11 \mathrm{kB}$ ser-1 PCR product from genomic DNA including a 3.4 $\mathrm{kB}$ ser-1 promoter region. The ser- 1 PCR products were injected into ser-1 (ok345) animals at $\sim 50 \mu \mathrm{g} / \mathrm{ml}$ with $50 \mu \mathrm{g} / \mathrm{ml}$ Pofm-1::gfp, which is expressed in coelomocytes as the coinjection marker (Miyabayashi et al., 1999). The primers used for rescuing construct were: $5^{\prime}$, GGAAGTTCTGAATCAATCAGCCC, 3'; CTGCCAAATCTAGTTGAGGGTCC; for the nonrescuing construct, 5', TCTTCCCCAATGTTTCTCTCACTC, and 3', CTGCCAAATCTAGTTGAGGGTCC. The control extrachromosomal array containing only the transformation marker transgene, egEx23[Pofm-1::gfp], was generated by injection of ofm-1::gfp into ser1 (ok345) animals at $50 \mu \mathrm{g} / \mathrm{ml}$.

The strain expressing the ser-1 cDNA in muscle, ser-1 (ok345);egEx26[Pmyo-3::ser-1(+);Pofm-1::gfp], was generated by fusion of the muscle-specific myo-3 promoter (Okkema et al., 1993) to the ser-1 cDNA. ser- 1 cDNA was isolated by reverse transcription (RT)-PCR from poly A-isolated RNA using the SuperScript First-Strand Synthesis System for RT-PCR (Invitrogen, San Diego, CA). Primers used for cDNA isolation were: 5', ATGGGAATCTACCATTTCAACGG; and 3', CCTTAAATTTCAGATTTTTATCAGG. The following primers were used for amplifying the myo-3 promoter from genomic DNA: 5', GGCTCAACAAAGATCAGGTGAC; and 3', GAAATGGTAGATTCCCATTTCTAGATGGATCTAGTGGTC. The fusion product was generated using the primers: 5', CCTTAAATTTCAGTTTTTATCAGG; and 3', CCTTAAATTTCAGATTTTTATCAGG. The Pmyo-3::ser-1 fusion product was injected into ser-1 animals at $\sim 50 \mu \mathrm{g} / \mathrm{ml}$ along with ofm-1::gfp as a coinjection marker. The mod-1 rescuing transgene, egEx24[mod-1(+);Pofm-1::gfp], was made by injection of a $6.7 \mathrm{kB}$ PCR product of the genomic mod-1 gene containing $2 \mathrm{kB}$ of DNA upstream of the mod- 1 open reading frame and $706 \mathrm{bp}$ of the $3^{\prime}$-UTR at $\sim 50 \mu \mathrm{g} / \mathrm{ml}$ along with ofm-1::gfp $(50 \mu \mathrm{g} / \mathrm{ml})$ as a coinjection marker into mod-1;ser-1 mutant animals. Rescue of mod-1 function was assayed 
by testing for restored sensitivity to 5 -HT on thrashing in liquid (Ranganathan et al., 2000) before testing for effects on egg laying. The primers used to generate the genomic mod-1 were: 5', CTGCTAAAAGTGGTAGGTTAGC; and 3', AGTATCAAGTCGAGGAAGACAG. The strain expressing mod-1(+) under the tph-1 promoter ser-1(ok345);mod-1(ok103);egEx29[Ptph-1::mod-1(+); Pofm-1::gfp] was generated by fusion of a $3.1 \mathrm{kB}$ promoter of the $t \mathrm{ph}-1$ gene to a genomic fragment containing the entire mod-1 open reading frame and $706 \mathrm{bp}$ of its $3^{\prime}$-UTR. The primers for generating the $t p h-1$ promoter for fusion with mod-1 were: $5^{\prime}$, TTGCAATACTAATAGGGAGTGC; and 3', AGTATCAAGTCGAGGAAGACAGTTCAGGAATAAACTTCATAATCACTCTTTTTGCACAAATATCC. The primers for generating the genomic fragment containing mod-1 were: 5', ATGAAGTTTATTCCTGAAATCACAC; and 3', AGTATCAAGTCGAGGAAGACAG. The primers for the fusion of the $t p h-1$ promoter and the mod-1 open reading frame were: $5^{\prime}$, GTGCAAGACTATTAGGGAGTGC; and 3', GTTCTCTCTACTTGTGTTACTTGCAGG.

\section{Results}

ser-1 animals are defective in 5-HT-mediated

egg-laying behavior

We obtained a strain with a deletion in the ser-1 gene. ser1 (ok345) has a deletion of 859 base pairs coupled with an insertion of 24 base pairs, which together result in a predicted truncation of the last third of the SER-1 protein (C. elegans Gene Knockout Consortium). Under standard culture conditions, the ser-1 mutant has no gross behavioral defects in locomotion, pharyngeal pumping, egg laying, or male mating, all of which are behaviors modulated by 5-HT (Horvitz et al., 1982; Loer and Kenyon, 1993; Duerr et al., 1999; Nurrish et al., 1999; Sawin et al., 2000; Sze et al., 2000). However, we found that ser-1 mutant animals are remarkably resistant to exogenous 5-HT with regard to egg laying in liquid. Wild-type animals lay few eggs when transferred to M9 buffer ( $1.3 \pm 0.2$ per animal in $90 \mathrm{~min})$. Addition of 5-HT to the media stimulates them to lay a large number of eggs (14.7 \pm 0.8 per animal in $90 \mathrm{~min}$ ) (Fig. $1 \mathrm{~A}$ ). ser- 1 mutant animals, in contrast, show complete resistance to exogenous 5-HT, laying only $0.3 \pm 0.1$ eggs per animal in $90 \mathrm{~min}$ (Fig. $1 \mathrm{~A}$ ). In fact, 56 of 64 ser- 1 mutant animals laid no eggs during 5-HT treatment, whereas only 2 of 64 wild-type animals laid no eggs (Fig. $1 A$ ).

The deletion in ser-1(ok345) disrupts approximately the last third of the open reading frame, so it is possible that the gene product may have partial function. To test whether the phenotypes observed are attributable to loss of ser-1 function, we examined the effect of 5-HT on egg laying in animals in which we have reduced levels of the ser-1 transcript by RNA-mediated interference (Fire et al., 1998; Montgomery and Fire, 1998). Like ser1(ok345) mutant animals, ser-1 RNAi animals displayed resistance to the stimulatory effects of exogenous 5-HT on egg laying in liquid: 32 of 61 ser-1 RNAi animals laid no eggs (Fig. $1 B$ ), and, overall, these animals laid fewer eggs compared with control animals (number of eggs per animal in $90 \mathrm{~min}$, ser-1 RNAi, $2.5 \pm$ 0.5 ; control RNAi, $12.5 \pm 0.8 ; p<0.001)$. The similarity in the phenotype of ser-1(ok345) mutant animals and ser-1 RNAi animals suggests that $\operatorname{ser}-1(\mathrm{ok} 345)$ is a loss-of-function mutation. We found that 5-HT failed to stimulate egg laying in a strain in which the ser-1(ok345) allele was placed heterozygous to a deficiency of the chromosomal region containing the ser- 1 gene (number of eggs per animals in $90 \mathrm{~min}, 0.0 \pm 0 ; p<0.001$ ) (Fig. $1 B)$, further indicating that ser-1(ok345) is a strong loss-offunction allele. The lack of stimulation of egg laying by 5-HT resulting from loss of ser- 1 demonstrates that ser- 1 is responsible for the ability of animals to lay eggs in response to exogenous 5-HT.

We also examined the egg-laying behavior of ser-1 mutant

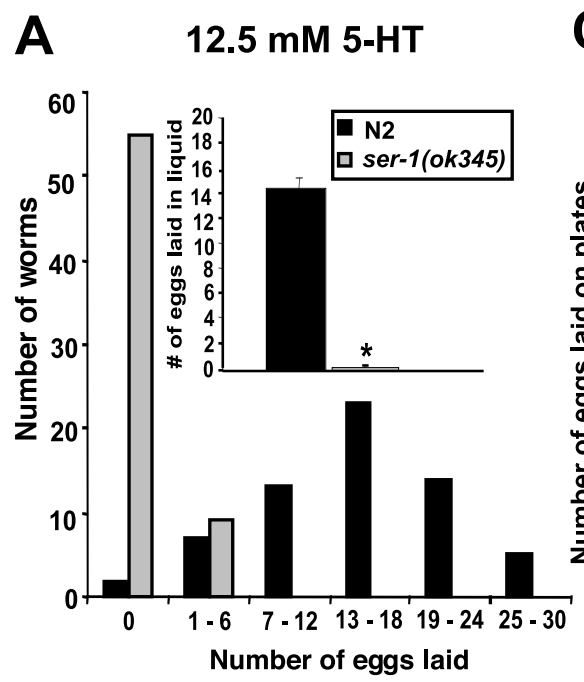

C $0 \mathrm{mM} \mathrm{5-HT}$

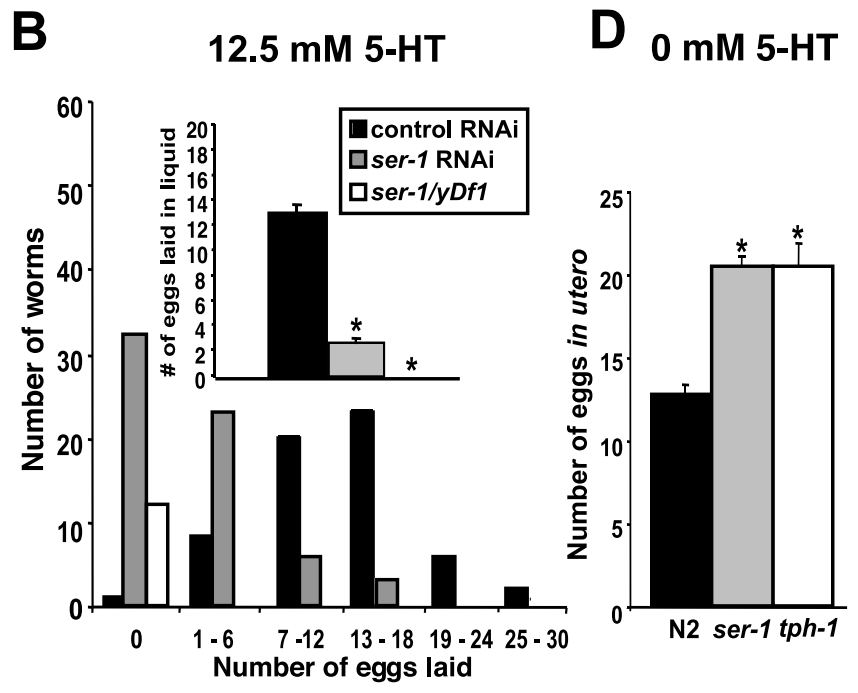

Figure 1. ser-1 mutant animals are defective in 5-HT-mediated egg-laying behavior. $\boldsymbol{A}$, ser- 1 mutant animals are resistant to the stimulatory effects of exogenous 5-HT on egg laying in liquid. Single animals were placed into liquid M9 buffer containing $12.5 \mathrm{~mm} 5-\mathrm{HT}$ for $90 \mathrm{~min}$, and the number of eggs laid was counted. $n=64$ for each genotype. The inset shows the average number of eggs laid per individual animal. $\boldsymbol{B}$, ser-1 RNAi animals and ser-1(ok345) over a deficiency in the ser- 1 gene are resistant to the stimulatory effects of exogenous 5-HT on egg laying in liquid. Single wild-type animals fed bacteria expressing the double-stranded RNA homologous to ser-1 and ser-1(ok345) placed heterozygous to a deficiency of the chromosomal region containing the ser-1 gene (ser-1/yDf1) were placed into liquid M9 buffer containing 12.5 mM 5-HT for 90 min, and the number of eggs laid was counted. $n=64$ for each RNAi group and $n=12$ for ser-1/yDf1. The inset shows the average number of eggs laid per individual animal. C, ser-1 and tph-1 mutant animals display a lower rate of egg laying in the absence of exogenous 5-HT compared with wild type on plates. Ten animals were assayed on NGM plates seeded with bacteria for $60 \mathrm{~min}$, and the number of eggs laid was counted for each trial. $n=9$ trials for wild type and ser-1. $n=6$ trials for tph-1. D, ser-1 mutant animals retain more eggs in utero compared with wild type. A higher than normal number of unlaid eggs within the uterus is indicative of defects in egg laying. The 5-HT-deficient mutant tph-1 is a known egg-laying defective mutant (Sze et al., 2000). The number of eggs per individual was counted. $n=40$ animals for wild type and ser- 1 and $n=20$ animals for $t p h-1$. Error bars indicate SEM. The asterisk indicates a statistical difference from wild type (N2); $p<0.001$; Mann-Whitney U test.

animals on plates in the absence of exogenous 5-HT. Wild-type animals placed on a plate with food will lay eggs at a rate of $4-10$ eggs per animal per hour (Waggoner et al., 1998). We found that ser-1 mutant animals laid significantly fewer eggs than wild-type animals (number of eggs per 10 animals in $60 \mathrm{~min}$, ser-1, $60 \pm 3$, wild type, $78 \pm 3 ; p<0.001$ ) (Fig. 1C). Mutants defective in the production of 5-HT, cat-4 and bas-1 (Waggoner et al., 1998) and 
tph-1 (Fig. 1C), also have lower rates of egg laying on plates. $C$. elegans hermaphrodites produce self-fertilized eggs that develop within the uterus and are released during short active phases of egg laying that are followed by periods of inactivity (Waggoner et al., 1998). Egg-laying-defective (Egl) mutants have been shown to hold more eggs in utero than wild-type animals. We found that, similar to the 5-HT-deficient mutant, tph-1 (Sze et al., 2000), ser-1 mutant animals hold more eggs than wild-type animals (number of eggs in utero, ser-1, $20.4 \pm 0.9$; wild type, $12.9 \pm 0.5$; $p<0.001 ;$ tph-1, $20.4 \pm 1.5)$ (Fig. 1D).

\section{ser-1 functions in vulval muscles}

Exogenous 5-HT might exert its stimulatory effect on neurons or directly on the muscles that mediate egg laying. We therefore sought to identify the cells in which ser-1 is expressed. We first performed transformation rescue with genomic fragments containing the ser-1 open reading frame. We found that the open reading frame and a promoter length of $\geq 7 \mathrm{kB}$ was sufficient to rescue the egg-laying defects (Fig. $2 \mathrm{~A}$ ) (data not shown). We made a reporter construct containing $8 \mathrm{kB}$ of the upstream promoter region of ser-1 fused to $g f p$ (Chalfie et al., 1994). This construct revealed expression in a greater number of cells than had been reported previously in which a translational fusion containing a $1.7 \mathrm{kB}$ upstream region was used (Tsalik et al., 2003). Animals expressing a Pser-1::gfp transgene containing a $3.4 \mathrm{kB}$ upstream promoter region failed to express $g f p$ in the vulval muscles but did express $g f p$ in many of the other cells seen with the 8 $\mathrm{kB}$ promoter reporter construct. In addition to the previously reported expression in pharyngeal muscle and neuronal processes in the nerve ring, we observed, beginning at the L1 larval stage, expression of $g f p$ in neurons in the head, neurons in the tail (including PVT and PVQ), ventral cord motorneurons (Fig. 2 B), and in adults in vulval muscle (Fig. $2 C$ ) and uterine cells. We also observed faint expression of $g f p$ in the posterior intestine. We did not observe expression in the HSNs or VC neurons, which are known to regulate egg-laying behavior (Trent et al., 1983; Bany et al., 2003). Absence of ser-1 in these neurons is consistent with the fact that animals lacking functional HSNs or VC neurons are still capable of 5-HT-dependent stimulation of egg laying (Trent et al., 1983; Waggoner et al., 1998).

The expression of $g f p$ in the vulval muscles suggests that ser-1 may be acting in vulval muscles to mediate the stimulatory effect of 5-HT on egg laying. To test this hypothesis, we expressed the ser- 1 cDNA using the muscle-specific myo-3 promoter (Okkema et al., 1993) to determine whether it could rescue 5-HT-induced egg laying. Consistent with this hypothesis, we found the Pmyo-3::ser-1(+) transgene partially restored 5-HT-dependent egg laying to ser-1(ok345) animals (Fig. 2A). A wild-type ser-1 transgene with the same $3.4 \mathrm{kB}$ promoter that failed to express $g f p$ in the vulval muscles also failed to rescue the egg-laying defects of the ser-1 mutant animals (Fig. $2 A$ ). These results indicate that ser- 1 expression in muscle can restore egg laying. Previous studies have indicated that 5 -HT acts on vulval muscle to stimulate egg laying (Trent et al., 1983; Brundage et al., 1996; Waggoner et al., 1998; Bastiani et al., 2003; Shyn et al., 2003). Our results indicate that ser-1 mediates this response.

\section{Pharmacological characterization of the ser-1 mutant}

We performed pharmacological studies to further elucidate the role of the SER-1 receptor in egg-laying behavior. ser-1 has high sequence homology to mammalian $5-\mathrm{HT}_{2}$ receptors (Hamdan et al., 1999). It has been reported previously that $\alpha$-methyl-5-HT, a $5-\mathrm{HT}_{2}$ receptor agonist, stimulates egg laying in liquid for $C$.
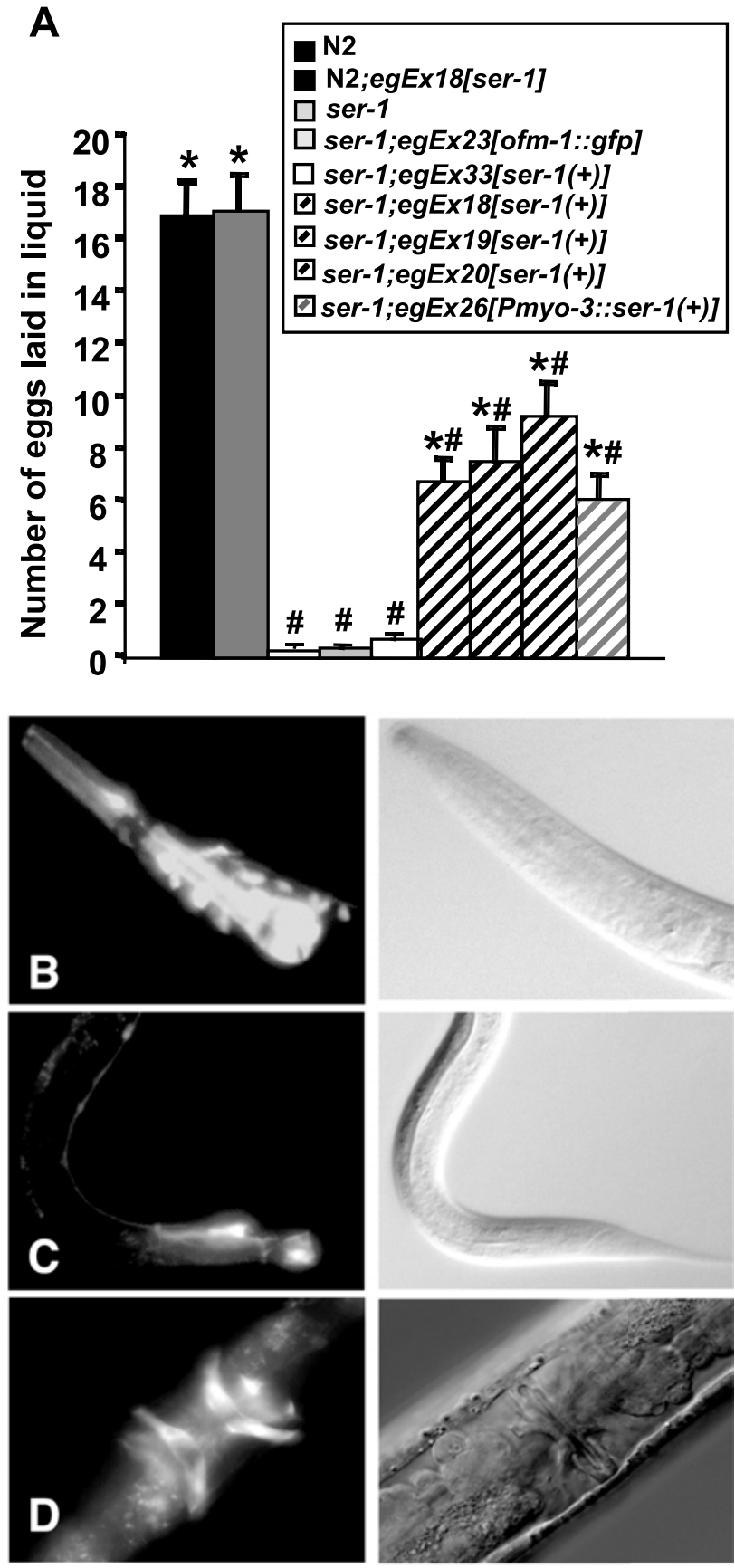

Figure 2. Rescue and expression pattern of ser-1. $\boldsymbol{A}$, Rescue of the resistance to 5-HTinduced egg laying in ser- 1 mutant animals in liquid. Three transgenic ser- 1 strains containing the ser-1 open reading frame and a $7 \mathrm{kB}$ upstream promoter (ser-1;egEx18[ser-1(+)], ser-1; egEx19[ser-1(+)], ser-1;egEx20[ser-1(+)]) showed a restored 5-HT-induced egg-laying response. The control strain (ser-1;egEx23[Pofm-1::gfp]) carrying an array containing only the coinjection marker, ofm-1::gfp, showed no rescue of the ser-1 mutant egg-laying behavior nor did the strain ser-1;egEx33[ser-1(+);Pofm-1::gfp] containing a $3.4 \mathrm{kB}$ upstream promoter and ser-1 open-reading frame. Overexpression of ser-1 in a wild-type background (egEx18[ser$1(+)]$ ) behaved like wild-type for 5-HT-induced egg laying. Selective expression of ser-1 in muscles (ser-1;egEx26[Pmyo-3::ser-1(+)]) restored the 5-HT-induced egg-laying response. Single wild-type animals were placed into liquid M9 buffer containing $12.5 \mathrm{~mm} 5$-HT for $90 \mathrm{~min}$, and the number of eggs laid was counted. $n=24$ for each group. Error bars indicate SEM. The asterisk indicates a statistical difference from ser-1 mutant animals $(p<0.001)$, and the number sign indicates a statistical difference from wild-type animals (Mann-Whitney $U$ test). $\boldsymbol{B}, \boldsymbol{C}$, Expression pattern of Pser-1::gfp in L1 hermaphrodite larvae. Pser-1::gfp (egEx21) contains an $8 \mathrm{kB}$ upstream ser-1 promoter and is expressed in pharyngeal muscle, neurons in the head, ventral cord, and tail of L1 larvae. D, Expression of Pser-1::gfp(egEx21) in young adults. Pser-1::gfp is expressed in the vulval muscles in young adult hermaphrodites. 
A

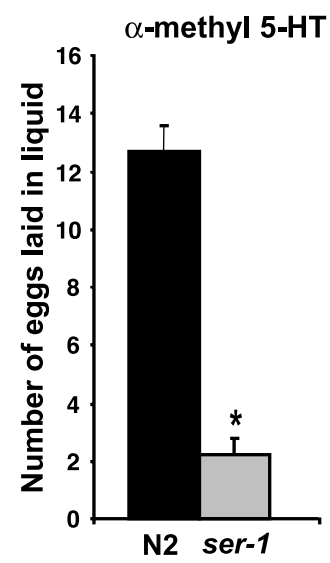

B

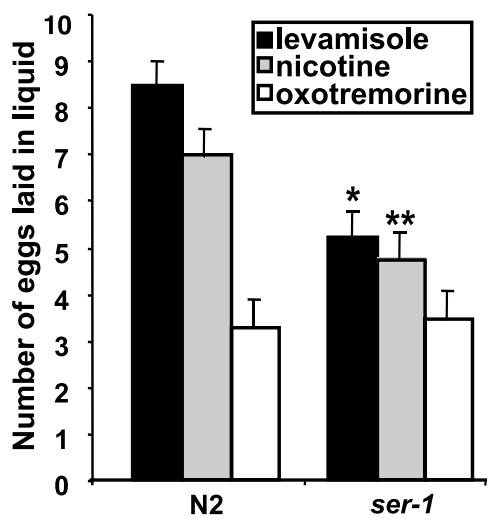

Figure 3. Pharmacological characterization of ser- 1 mutant animals in liquid. $\boldsymbol{A}$, The ser-1 mutant is resistant to the stimulatory effect of a $5-\mathrm{HT}_{2}$ receptor agonist, $\alpha$-methyl-5- $\mathrm{HT}$, on egg laying. Single $\mathrm{N} 2$ and ser- 1 animals were placed in water containing $125 \mu \mathrm{m} \alpha$-methyl-5-HT for $60 \mathrm{~min}$, and the number of eggs laid was counted. Number of eggs laid in water alone: N2, $2.9 \pm 0.61 ;$ ser- $1,1.8 \pm 0.56$ eggs laid in $60 \mathrm{~min} . n=48$ for each genotype. $B$, ser- 1 mutant animals are partially resistant to the cholinergic agonists levamisole and nicotine on egg laying. Single $\mathrm{N} 2$ and ser- 1 mutant animals were placed in liquid M9 buffer containing $50 \mu \mathrm{m}$ levamisole, $0.5 \%$ nicotine, or $20 \mathrm{~mm}$ oxotremorine for $90 \mathrm{~min}$, and the number of eggs laid was counted. Number of eggs laid in M9 buffer: N2, $1.3 \pm 0.2$; ser-1, $0.3 \pm 0.11 . n=48$ for each genotype. All error bars indicate SEM. ${ }^{*} p<0.001$ and ${ }^{* *} p<0.05$ (Mann-Whitney $U$ test); difference between $\mathrm{N} 2$ and ser- 1 animals.

elegans wild-type animals (Bastiani et al., 2003). We found that ser-1 mutant animals were resistant to $\alpha$-methyl-5-HT-induced stimulation of egg laying in liquid (number of eggs laid per animal in $60 \mathrm{~min}$, ser- $1,2.2 \pm 0.6$, wild type, $12.7 \pm 0.6 ; p<0.001$ ) (Fig. 3A). This result indicates that the response to both 5-HT and a more specific $5-\mathrm{HT}_{2}$ receptor agonist is mediated by SER-1.

C. elegans wild-type animals are also stimulated to lay eggs in liquid by treatment with cholinergic agonists (Trent et al., 1983; Weinshenker et al., 1995). We were interested in determining whether or not the resistance to exogenous 5-HT affects the ability of ser-1 mutant animals to respond to the cholinergic agonists levamisole, nicotine, and oxotremorine. Both levamisole and nicotine activate nicotonic-type receptors, and oxotremorine activates muscarinic receptors. Compared with wild-type animals, ser-1 mutant animals displayed a statistically significant lower level of levamisole-induced egg laying (number of eggs laid in 90 min, ser-1, $5.2 \pm 0.6$, wild-type N2, $8.4 \pm 0.6 ; p<0.001$ ) (Fig. 3B) and a lower level of stimulation of nicotine-induced egg laying (number of eggs laid in $90 \mathrm{~min}, \mathrm{ser}-1,4.7 \pm 0.6$, wild-type N2, $6.9 \pm 0.9 ; p<0.05$ ) (Fig. 3B). Oxotremorine stimulated egg laying in both wild-type and ser-1 mutant animals to the same degree (number of eggs laid in $90 \mathrm{~min}$, ser-1, $3.4 \pm 0.7$, wild-type $\mathrm{N} 2,3.3 \pm 0.7 ; p<0.001$ ) (Fig. 3B). We also tested the effect of the acetylcholinesterase inhibitor, aldicarb, which has been shown to inhibit egg laying on plates (Bany et al., 2003) and found both wild-type and ser-1 mutant animals displayed a similar level of inhibition of egg laying (number of eggs laid per 10 animals: N2, control, $88 \pm 5$ vs aldicarb, $43 \pm 4$, and ser- 1 , control, $70 \pm 4$ vs aldicarb, $42 \pm 3$ ). Therefore, SER-1 appears to contribute to the function of the cholingeric stimulatory egg-laying pathway but not to the inhibitory or muscarinic egg-laying pathways. 5-HT plays a role in regulating the duration of the inactive egg-laying state, and acetylcholine plays a role in regulating the number of egg-laying events that occur during the active state (Waggoner et al., 1998). The reduction in levamisole and nicotine-induced egg laying of ser-1 mutant animals may reflect the fact that animals defective in 5-HT signaling are reported to spend less time in the active egg-laying phase (Waggoner et al., 1998).

\section{Loss of ser-1 function reveals an inhibitory effect of 5-HT on egg laying}

Wild-type animals lay few eggs in liquid unless treated with agents that induce egg laying such as 5-HT or levamisole (Trent et al., 1983; Weinshenker et al., 1995), making it difficult to assess the effect of 5-HT on basal egg-laying rate in solution. The reason for the observed decrease in egg laying is unclear; it may be because animals display distinct behavioral responses in liquid versus on solid substrates. Therefore, we examined the effect of 5-HT administration on the egg-laying behavior of ser-1 mutant animals on agar plates with food, conditions in which egg laying is promoted in wild-type animals. Although wild-type animals increase their egg-laying rate in the presence of 5-HT, surprisingly, ser-1 mutant animals exposed to 5-HT on agar plates for 60 min displayed a significantly lower rate of egg laying compared with untreated ser-1 mutant animals (number of eggs laid per 10 animals: 0 mm 5-HT, $37 \pm 4 ; 7.5$ mm 5-HT, $7 \pm 2 ; p<0.001$ ) (Fig. $4 A)$. This result indicates that there is an inhibitory effect of 5-HT on egg laying that is unmasked by loss of the SER-1 receptor. An acute inhibitory effect of 5-HT on egg laying has not been observed previously in C. elegans. The inhibition of egg laying by 5 -HT in the ser-1 mutant suggests that there might be a 5-HT receptor that negatively regulates egg laying in C. elegans. To test this hypothesis, we constructed a double mutant with ser-1 and mod-1, which encodes a 5-HT-gated chloride channel that we suspected may mediate this inhibition. After exposure to 5-HT on agar plates, the mod-1;ser-1 double mutant failed to display the inhibition in egg laying seen in the ser-1 single mutant (number of eggs laid per 10 animals: $0 \mathrm{~mm} 5$-HT, $41 \pm 4$; $7.5 \mathrm{~mm} 5$-HT, $37 \pm 4 ; p>0.73$ ) (Fig. $4 A$ ). In addition, we were able to restore the 5-HT-mediated inhibition of egg laying by reintroducing the wild-type mod-1 gene into ser-1;mod-1 mutant animals (number of eggs laid per 10 animals: $0 \mathrm{~mm} \mathrm{5-HT,} 42 \pm 3$; $7.5 \mathrm{~mm} 5-\mathrm{HT}$, $20 \pm 2 ; p<0.001$ ) (Fig. $4 A$ ). These results suggest that the MOD-1 channel mediates the inhibitory effect of 5-HT on egg laying. The mod-1 single mutant does not appear to have obvious defects in egg laying and retains a similar number of eggs in utero as wild-type animals (data not shown). The mod-1 single mutant does appear to be slightly more responsive to exogenous 5-HT than wild-type animals, because it lays a larger number of eggs than wild type (number of eggs laid per 10 animals in $60 \mathrm{~min}: \mathrm{N} 2$, $131 \pm 3 ;$ mod $-1,166 \pm 8 ; p=0.0012$ ) (Fig. $4 A$ ). This difference in egg laying may be attributable to an absence of a basal inhibitory response in the mod-1 mutant animals.

Previous imaging studies have demonstrated that exogenous 5-HT can decrease the frequency of calcium transients in the HSNs (Shyn et al., 2003), so we used egl-1 mutant animals, which lose their HSNs during development through aberrant programmed cell death (Desai et al. 1988) to ask whether the HSNs play a role in the 5-HT-mediated inhibition of egg laying. We constructed a ser-1;egl-1 double mutant and asked whether the inhibitory effect of 5-HT on egg laying was still evident. Because egl-1 mutant animals lay few eggs normally, we predicted that it might be difficult to assess a 5-HT-dependent inhibitory effect in the ser-1;egl-1 mutant animals. To our surprise, we observed a significant increase in egg laying after treatment with $5-\mathrm{HT}$ (number of eggs laid per 10 animals: $0 \mathrm{~mm}$ 5-HT, $4 \pm 1 ; 7.5 \mathrm{~mm}$ 5 -HT, $32 \pm 4 ; p<0.001)$. These results suggest the intriguing 
A

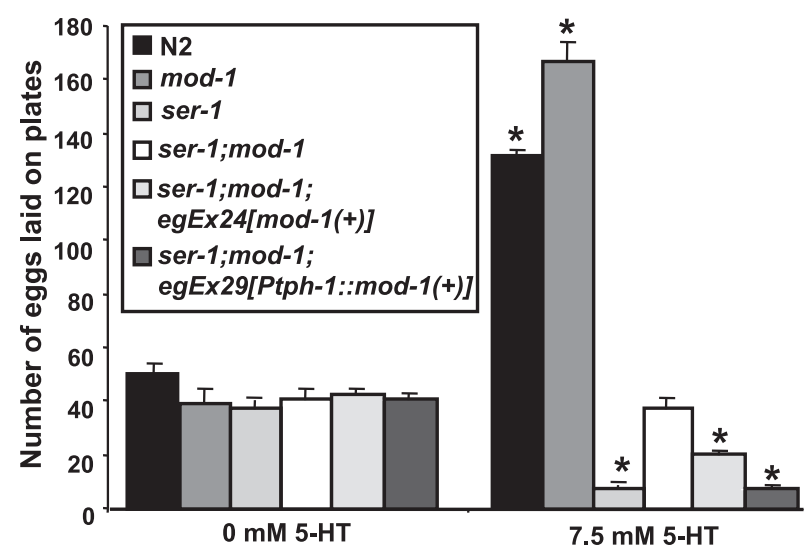

B

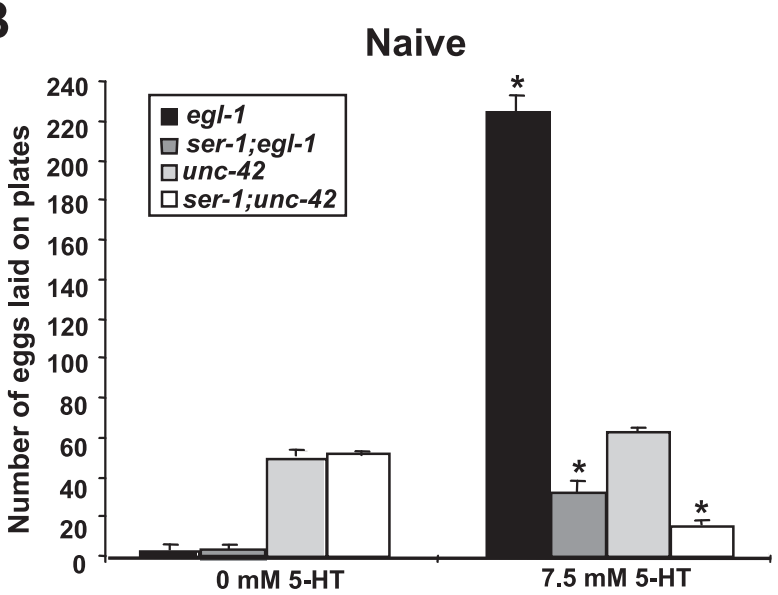

C

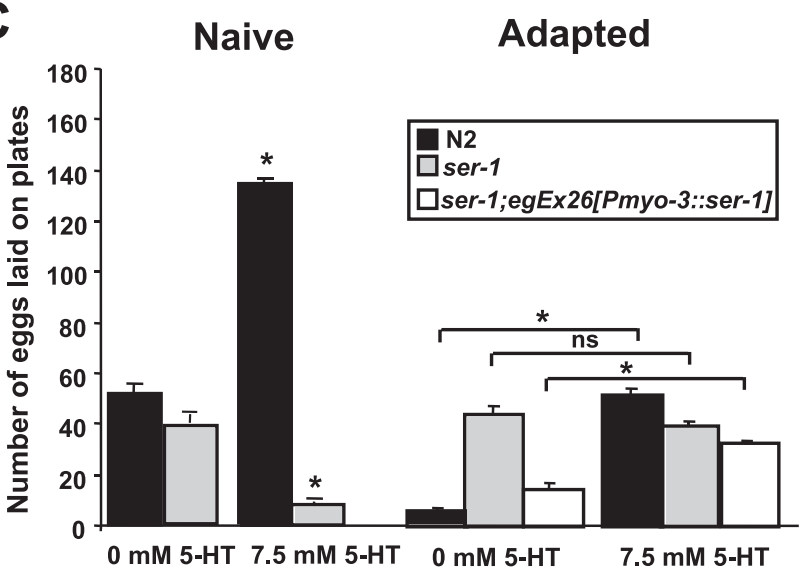

Figure 4. Inhibitory effects of 5-HT on egg laying are revealed in ser- 1 mutant animals on agar plates. A, Acute exposure to 5-HT on agar plates inhibits egg laying of ser- 1 mutant animals in a mod-7-dependent manner. ser-1 mutant animals display an inhibition of egg laying on 7.5 mм 5-HT compared with 0 mм 5-HT that is not seen in wild-type animals. ser-1; mod-1 mutant animals display no inhibition of egg laying by 5 -HT indicating that MOD-1, a 5-HT-gated chloride channel, is required for the inhibition of egg laying by 5 -HT. Transgenic ser-1;mod-1 animals containing mod-1(+) expressed under the control of either its own promoter or the tph-1 promoter are rescued for the inhibition of egg laying seen in ser- 1 mutant animals. Ten animals were placed on agar plates containing $7.5 \mathrm{~mm} 5-\mathrm{HT}$ for $60 \mathrm{~min}$, and the number of eggs laid was counted for each trial. $n=20$ trials for wild type and ser- 1 for each condition. $n \geq 8$ trials for other genotypes and conditions. $\boldsymbol{B}$, Role of HSNs and VC neurons in the 5-HT-dependent inhibition of egg-laying behavior. Double mutants were made between ser-1 and egl-1 (egl-1 mutants are defective in HSN function) and between ser- 1 and unc-42 (unc-42 mutants are defective in VC neuron function). Ten animals were placed on agar plates containing $7.5 \mathrm{~mm}$ 5-HT for $60 \mathrm{~min}$, and the number of eggs laid was counted for each trial. ser-1;egl-1 mutant possibility that there are at least three separate responses to $5-\mathrm{HT}$ in the egg-laying pathway. SER-1 is responding to 5-HT by stimulating egg laying, and MOD-1 is mediating an inhibition of egg laying. In addition, there is another 5-HT induction of egg laying that is independent of the ser-1 pathway and the HSNs.

The VC neurons make synaptic connections with the HSNs (White et al., 1986) and are immunoreactive for 5-HT (Rand and Nonet, 1997; Duerr et al., 1999), so we examined the role of the VC neurons in mediating the 5-HT-dependent inhibition of egg laying. Ablation of $\mathrm{VC}$ neurons or genetic disruption of their function results in animals that are hyperactive for egg laying, indicating an inhibitory role for these neurons in egg laying (Bany et al., 2003). We made a double mutant with ser-1 and a mutant defective in VC neuron function, unc-42 (Bany et al., 2003), which encodes a transcription factor important for the fate and function of many neurons (Wightman et al., 1997; Baran et al., 1999). We tested both unc-42 and ser-1;unc-42 mutant animals for their egg-laying behavior in response to 5-HT. unc-42 mutant animals are hyperactive for egg laying and show a slight increase in egg laying in response to exogenous 5-HT (number of eggs laid per 10 animals: $0 \mathrm{~mm} 5-\mathrm{HT}, 52 \pm 3$; 7.5 mM 5-HT, $62 \pm 2 ; p=$ 0.012 ). The ser-1;unc-42 mutant animals, like ser-1 mutant animals, displayed a 5-HT-mediated decrease in egg laying (number of eggs laid per 10 animals: $0 \mathrm{~mm} 5-\mathrm{HT}, 53 \pm 2 ; 7.5 \mathrm{~mm} 5$-HT, $14 \pm 2 ; p<0.001$ ), suggesting that the inhibitory effects of 5-HT on egg laying do not depend on VC neuron function.

We tested whether expression of mod-1 in the HSNs could restore the inhibitory effects of 5-HT on egg laying in a mod-1 mutant. We expressed the mod-1 gene using the tph-1 promoter, which selectively drives expression in serotonergic neurons, including the HSNs (Sze et al., 2000). The Ptph-1::mod-1 transgene restored the 5-HT-dependent inhibition of egg laying in ser-1; mod-1 mutant animals (number of eggs laid per 10 animals: $0 \mathrm{~mm}$ 5-HT, $40 \pm 2 ; 7.5$ mm 5-HT, $7 \pm 1 ; p<0.001$ ) (Fig. $4 A$ ). This result appears to reflect a 5 -HT-dependent effect on egg laying, because in the absence of 5-HT, these animals laid a similar number of eggs as ser-1;mod-1 mutant animals (number of eggs laid per 10 animals: ser-1;mod-1;egEx29[Ptph-1::mod-1], $40 \pm 3$; ser1;mod-1, $41 \pm 4 ; p=0.813$ ) (Fig. $4 A$ ). This result, together with the analysis of egl-1 mutants (above) suggests that the HSNs are the effectors of the 5-HT-mediated inhibition of egg laying.

mod-1 has been reported to be expressed in neurons (Ranganathan et al., 2000), but it has not been reported to be expressed specifically in the HSNs or VC neurons. We generated a Pmod-1::gfp using the same promoter length required for the rescue of the egg-laying phenotype, and we observed expression in a number of neurons in the head, but did not observe expres-

$\leftarrow$

animals treated with 5-HT increased their rate of egg laying on 5-HT, whereas the ser-1; unc-42 decreased their rate of egg laying. $n \geq 12$ trials for each genotype and condition. C, Chronic exposure to 5-HT eliminates the 5-HT-dependent inhibition of egg laying in ser- 1 mutant animals and produces a withdrawal effect on wild-type animals. Ten animals were pretreated on plates containing $7.5 \mathrm{~mm} 5-\mathrm{HT}$ for $4-5 \mathrm{~h}$. Animals were then transferred to plates containing 0 or $7.5 \mathrm{~mm}$ serotonin for $60 \mathrm{~min}$, and the number of eggs laid was counted. After 5 -HT treatment, ser- 7 mutant animals do not display inhibition of egg laying in the presence of 5-HT. After 5-HT treatment, wild-type animals no longer show stimulation of egg laying in the presence of 5-HT (adaptation) but rather show inhibition of egg laying in the absence of 5-HT (withdrawal). Adapted-ser-1 mutant animals fail to display withdrawal effects in the absence of 5-HT. ser-1 mutant animals expressing ser- 1 in muscles restores the withdrawal response and adaptation to the inhibitory effects on egg laying. $n=14$ trials for each genotype and condition. Error bars indicate SEM. The asterisk indicates a statistical difference between $0 \mathrm{~mm} 5-\mathrm{HT}$ and $7.55-\mathrm{HT} \mathrm{mm}$; $p<0.001$; Mann-Whitney $U$ test. 
sion in either the HSNs or VC neurons (data not shown). Although we cannot rule out the possibility that Pmod-1::gfp is expressed in the HSNs at too low a level to be detected, our results suggest that mod-1 functions in neurons upstream of the HSNs to inhibit egg laying. In support of this, Wenick and Hobert (2004) reported that mod-1 is expressed in AIY, an interneuron which synapses onto the HSNs.

\section{Adaptation and withdrawal occur during exposure to exogenous 5-HT}

C. elegans undergoes adaptation to the stimulatory effects of exogenous 5-HT on egg laying; wild-type animals treated overnight on plates containing 5-HT become egg-laying defective (Schafer and Kenyon, 1995). We were interested in whether animals that lack the stimulatory SER-1 receptor would display any adaptive responses to 5-HT on egg laying. We treated wild-type and ser-1 mutant animals on 5-HT plates for $4-5 \mathrm{~h}$ to allow adaptation to develop and then tested their responses to 5-HT. After this treatment in wild-type animals, 5-HT no longer stimulates egg laying, and animals lay a similar number of eggs on $7.5 \mathrm{~mm}$ 5-HT plates as naive animals on $0 \mathrm{~mm} 5$-HT plates (number of eggs laid per 10 animals in $60 \mathrm{~min}$ : adapted, $50 \pm 3$; naive, $50 \pm 4 ; p>0.84$ ) (Fig. $4 C)$. ser- 1 mutant animals exposed to 5 -HT for $4-5 \mathrm{~h}$ displayed a different form of adaptation. Naive ser- 1 mutant animals initially after exposure to 5-HT display an inhibition of egg laying that diminishes over time (number of eggs laid per 10 animals in 60 min: naive, $7 \pm 2$; adapted, $38 \pm 2 ; p<0.001$ ) (Fig. $4 C$ ). Adapted ser-1 mutant animals lay a similar number of eggs as naive ser-1 mutant animals on $0 \mathrm{~mm} 5$-HT (number of eggs laid per 10 animals in $60 \mathrm{~min}$ : adapted on $7.5 \mathrm{~mm} 5-\mathrm{HT}, 39 \pm 3$; naive on 0 mм 5-HT, $37 \pm 4 ; p>0.98$ ) (Fig. $4 C$ ). These results suggest that after chronic exposure ( $4-5 \mathrm{~h})$, C. elegans can modulate both the acute inhibitory and stimulatory responses to 5-HT on egg-laying behavior.

We observed that adapted wild-type animals display an additional behavior that has not been reported previously. Adapted wild-type animals that were transferred to plates without 5-HT exhibited a strong inhibition of egg laying after removal from 5-HT (number of eggs laid per 10 animals in $60 \mathrm{~min}: 0 \mathrm{~mm}$ 5-HT, $6 \pm 1 ; 7.5$ mM 5-HT, $51 \pm 3 ; p<0.001$ ) (Fig. 4C). This result suggests that after prolonged exposure to exogenous 5-HT, animals develop a dependence on 5-HT to sustain a normal egglaying rate. This development of dependence on 5-HT for egglaying probably does not represent a normal response to endogenous 5-HT but rather has more similarity to withdrawal responses seen with repeated or chronic exposure to neuroactive drugs. We found that this effect is reversible; animals show recovery from withdrawal after a few hours (data not shown). In contrast, we found that adapted ser-1 mutant animals did not display this withdrawal response. Adapted ser-1 mutant animals transferred to $0 \mathrm{~mm}$ 5-HT plates laid as many eggs as ser-1 mutant animals transferred to $7.5 \mathrm{~mm} 5$-HT plates (number of eggs laid per 10 animals in $60 \mathrm{~min}: 0 \mathrm{~mm} 5-\mathrm{HT}, 44 \pm 4$; $7.5 \mathrm{~mm} 5-\mathrm{HT}, 39 \pm$ $3 ; p>0.29$ ) (Fig. $4 B$ ). These results suggest that the withdrawal response is dependent on the SER-1 receptor. To further examine the dependence of withdrawal on SER-1, we tested whether expressing ser- 1 only in the muscle under control of the myo-3 promoter could rescue the withdrawal response. We found that ser-1 muscle expression restored the wild-type withdrawal response to the ser-1 mutant animals (number of eggs laid per 10 animals in 60 min: 0 mm 5-HT, $14 \pm 3 ; 7.5$ mm 5-HT, $32 \pm 2 ; p<$ 0.007 ) (Fig. $4 B$ ). Expression of ser- 1 in muscle also restores the adaptation to the stimulation of egg laying (number of eggs laid per 10 animals in $60 \mathrm{~min}$ : naive $7.5 \mathrm{~mm} 5-\mathrm{HT}, 71 \pm 3$; adapted 7.5 mM 5-HT, $32 \pm 2 ; p<0.001)$. Together, these results suggest that SER-1 can function in muscle to mediate the 5-HT-dependent stimulation and adaptive responses on egg laying.

\section{SER-1 is required for 5-HT-dependent male mating behavior}

We tested ser-1 mutant animals for defects in other behavioral responses to exogenous 5-HT. ser- 1 mutant animals were sensitive to exogenous 5-HT for stimulation of pharyngeal pumping and inhibition of locomotion to a degree similar to wild-type animals (data not shown). However, we observed a difference in the response of ser-1 mutant males to treatment with exogenous 5-HT. C. elegans males perform a stereotypical series of behavioral steps during male mating consisting of response to contact with the hermaphrodite, turning, vulva recognition, spicule insertion, and sperm transfer (Liu and Sternberg, 1995). The turning behavior consists of a tight ventral inward curl of the male tail that is used to maintain continuous contact with the hermaphrodite when turning from one side of the hermaphrodite to the other. Both the ability to turn and the timing of the turn are important for efficient performance of this task (Liu and Sternberg, 1995). Six male-specific serotonergic motorneurons (the CP neurons) innervate the male-specific diagonal muscles (White et al., 1986) and laser killing of either the CP motorneurons or the diagonal muscles produces defects in the ability of males to perform the turning step of mating (Loer and Kenyon, 1993). When exposed to exogenous 5-HT, males curl their tails ventrally (Loer and Kenyon, 1993). After treatment with $20 \mathrm{~mm}$ 5-HT, we found that ser-1 mutant males curled their tails $18 \%$ of the time, whereas wild-type males displayed tail curling $80 \%$ of the time (Fig. 5A). The resistance of ser-1 mutant males to 5-HTinduced tail curling suggests that SER-1 may function in males to mediate this step of male mating behavior. We examined the expression pattern of Pser-1::gfp (egEx21) in males. In addition to pharyngeal muscle and neuronal expression similar to that observed in hermaphrodites, there was a low level of expression in the male-specific diagonal muscles (Fig. 5B). The 5-HTdependent tail-curling response could be rescued by the expression of the wild-type ser-1 gene both under control of its own promoter and under control of the muscle-specific myo-3 promoter (Fig. 5A). Together, the expression pattern in the diagonal muscles and rescue by muscle-specific ser-1 expression support the notion that SER-1 functions in these muscles to mediate tail curling.

Because MOD-1 is involved in the 5-HT-dependent-egglaying response in hermaphrodites, we asked whether there is a role for MOD-1 in the 5-HT-dependent male tail-curling response. mod-1 mutant males show a decrease in 5-HT-dependent tail-curling response compared with wild-type males (45 \pm 5 vs $80 \pm 4 \% ; p<0.001)$. The mod-1;ser-1 double mutant demonstrated resistance to the 5-HT-dependent tail curling that was similar to that of ser- 1 single mutants ( $13 \pm 7$ vs $18 \pm 7 \%$; $p=$ 0.346 ), suggesting that these two genes act in the same pathway to mediate tail curling.

To determine whether this resistance to the 5-HT-dependent tail curling corresponds to deficits in male mating behaviors, we examined ser-1, mod-1, and ser-1;mod-1 mutant males for their ability to make proper turns during mating. Approximately $95 \%$ of the time, wild-type males will stop moving after initial contact with the vulva (Liu and Sternberg, 1995), limiting the number of turns a male makes before mating. To increase the number of observable turning events, we paired males with L4 hermaphrodites, which have not yet formed vulvas. We found that wild-type 

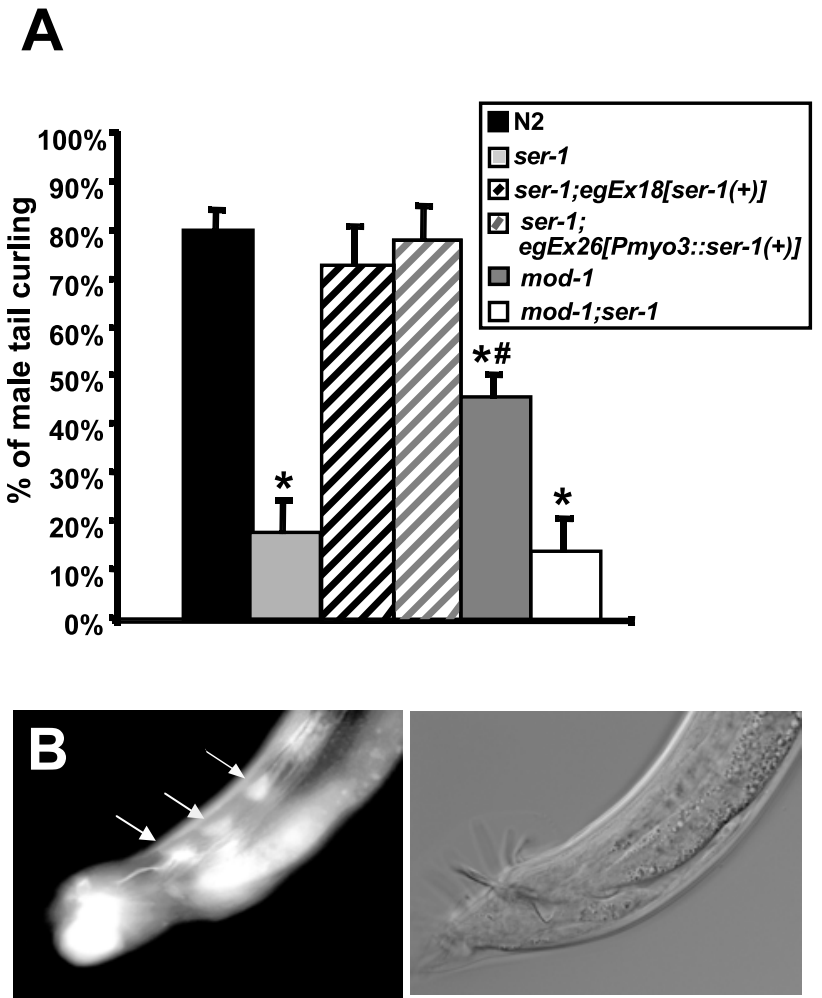

C

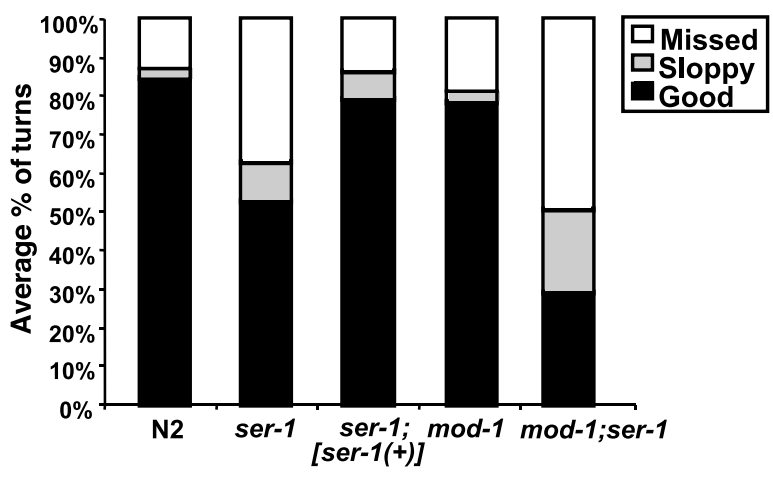

D

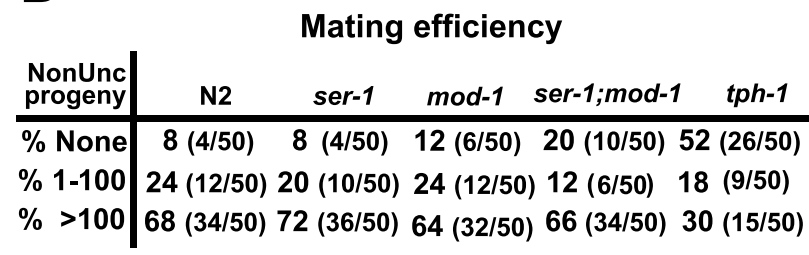

Figure 5. SER-1 is important for induction of ventral tail curling and male turning behavior. A, ser-1, mod-1, and mod-1;ser- 1 mutant males are resistant to the effects of exogenous 5 -HT on tail curling in liquid. Males were treated in M9 buffer containing $20 \mathrm{~mm} 5$-HT for $15 \mathrm{~min}$ (5 animals per well), and the number of males with curled tails was counted. Transgenic ser-1 males expressing the ser- 1 gene under its own promoter or under a muscle-specific promoter (myo-3) restore the tail-curling phenotype. Mutant males: $n \geq 9$ trials for each genotype. Error bars indicate SEM. The asterisk indicates a statistical difference between N2 and mutant males; $p<0.001$ (Student's $t$ test). The number sign indicates a statistical difference between ser-1 and mod-1; $p<0.001$ (Student's $t$ test). B, Expression pattern of Pser-1::gfp(egEx21) in males. In addition to neuronal expression observed in hermaphrodites (bright staining in the tail), fainter expression in the male diagonal muscles (arrows) is observed. C, Turning behavior of ser-1, mod-1, and mod-1;ser-1 males. Average percentage of good, sloppy, and missed turns per individual male is shown. $n=20$ for each genotype. The percentage of good turns is statistically different between wild-type $\mathrm{N} 2$ and mutant males ( $p<0.001$; Student's $t$ test) and between ser-1 and mod-1; ser- 1 mutant males ( $p<0.001$; Student's t test). D, Male mating efficiency of males made good turns (in which they reach the opposite side of the hermaphrodite while remaining in continuous contact) $\sim 85 \%$ of the time, sloppy turns (in which they reach the opposite side of the hermaphrodite but lose contact during the process) $\sim 2 \%$ of the time, and missed turns (in which they fail to turn at all) $\sim 13 \%$ of the time (Fig. $5 C$ ). ser- 1 mutant males, in contrast, make fewer good turns $(\sim 53 \%)$ and a higher percentage of sloppy and missed turns (10 and 37\%, respectively). Expression of the wild-type ser- 1 transgene restored the turning behavior of ser-1 mutant males (79\% good turns, 7\% sloppy turns, and $14 \%$ missed turns). mod-1 mutant males did not show a statistical difference from wild-type animals for turning behavior (Fig. 5C). However, the mod-1;ser-1 mutant males performed fewer good turns compared with ser-1 mutant males (29 vs 53\%). mod-1; ser-1 mutant animals demonstrate subtly exaggerated body bends when moving backwards, which may be important during mating because the male moves backward when its tail makes contact with the surface of the hermaphrodite. mod-1 mutant males are slightly less likely to stop after initial contact with the hermaphrodite. Defects in initial contact have been reported in 5-HTdeficient males and may be attributed to defects in sensory ray function (Loer and Kenyon, 1993). These defects in tail curling and turning did not prevent mating of these mutant males. We tested ser-1, mod-1, and ser-1;mod-1 mutant males for mating efficiency and found that they did not differ significantly from wild-type males, whereas the 5-HT-deficient mutant, tph-1, showed a decrease in mating efficiency (Fig. 5D). Our analysis indicates that ser- 1 and mod-1 together play a role in the turning event of the mating behavior but are not necessary for efficient mating, at least in laboratory conditions.

\section{Discussion}

We identified SER-1 as the 5-HT G-protein-coupled receptor responsible for the stimulatory effects of exogenous 5-HT on two sexually dimorphic behaviors of $C$. elegans, egg laying in hermaphrodites, and ventral tail curling in males. Dempsey et al. (2005) have also shown a similar result in ser-1 animals on egg laying in hermaphrodites. SER-1 is expressed in specific sets of muscles that mediate egg laying and male mating. Reconstruction of the C. elegans nervous system indicates that these muscles are innervated by neurons (White et al., 1976; White, 1988), which are serotonergic (Desai et al., 1988; Loer and Kenyon, 1993; Bargmann, 1998). Both the hermaphrodite-specific vulva muscles and the male-specific diagonal muscles are homologous tissues that are derived from the same postembryonic blast cell (Sulston and Horvitz, 1977). In addition to the defects observed in response to exogenous serotonin, ser-1 mutant animals display corresponding defects in egg laying and the turning step of male mating behavior in the absence of exogenous 5-HT.

In the absence of exogenous 5-HT, ser-1 mutant animals exhibit lower rates of egg laying on food and a higher number of eggs retained in utero, supporting a role for SER-1 in egg laying. Dempsey et al. (2005) have also shown a similar result in ser-1 animals. The defects observed in ser-1 mutant animals are consistent with the results observed in mutants defective in the synthesis of 5-HT (Sulston et al., 1975; Weinshenker et al., 1995; Duerr et al., 1999; Sze et al., 2000), which do not display obvious

$\leftarrow$

wild-type, ser-1, mod-1, and mod-1;ser-1 and tph-1 mutant males. A single unc-13 L4 hermaphrodite was placed onto an agar plate with a single $L 4$ mutant male. The number of cross progeny was determined by counting the number of non-Unc animals that were produced from the mating. $n=50$ for number of mating plates examined. 
Egl phenotypes. Although it has long been known that 5-HT plays a role in egg laying in C. elegans, neither mutations in ser- 1 nor in 5-HT biosynthesis genes were identified in screens for Egl animals, most likely because of the subtle nature of the resulting Egl defect.

Several of the GPCRs in C. elegans that regulate behavior have been identified by knock-out of candidate genes rather than in genetic screens (Suo et al., 2002; Bany et al., 2003; Chase et al., 2004). Mutants with defects in downstream targets of GPCRs, such as the G-proteins $\mathrm{G} \alpha_{\mathrm{q}}(e g l-30)$ and $\mathrm{G} \alpha_{\mathrm{o}}$ ( goa-1), are defective in egg laying and show resistance to the effects of exogenous 5-HT on egg laying (Mendel et al., 1995; Segalat et al., 1995; Brundage et al., 1996; Bastiani et al., 2003). egl-30 and goa-1 mutants display more severe defects in egg laying than does the ser-1 mutant possibly because of their expression in both the egg-laying neurons and egg-laying muscles (Mendel et al., 1995; Segalat et al., 1995; Bastiani et al., 2003) and/or activation by multiple neurotransmitter pathways. For example, in the HSNs, goa- 1 is activated by an unidentified serotonin-dependent GPCR, acetylcholine-dependent GPCRs, and another GPCR with a ligand that is unknown at present (Bany et al., 2003; Shyn et al., 2003; Moresco and Koelle, 2004).

We identified a previously uncharacterized 5-HT-mediated inhibitory pathway regulating egg-laying behavior, which is observed in ser-1 mutant animals exposed to exogenous serotonin on agar plates. This inhibition of egg laying by 5 -HT is dependent on MOD-1. mod-1 mutant animals are more sensitive to the stimulatory effects of 5-HT than wild-type animals, further supporting an inhibitory role for mod-1 in egg-laying behavior. Studies have demonstrated that exogenous 5-HT decreases activity in HSNs (Shyn et al., 2003), supporting the notion of inhibition of these neurons by 5 -HT. We found that mod-1 appears not to be expressed in the HSNs, consistent with a role for MOD-1 activity in neurons upstream of the HSNs in 5-HT-mediated inhibition of the HSNs. An additional role for MOD-1 in the inhibition of egg laying by dopamine has been proposed and reported to be independent of the HSN pathway (Dempsey et al., 2005). In contrast, our results indicate that the 5-HT-mediated MOD-1dependent inhibition of egg laying requires the HSN pathway.

MOD-1 may function to decrease neuronal activity by hyperpolarizing neurons in a similar manner to other ligand-gated chloride channels such as the $\mathrm{GABA}_{\mathrm{A}}$ receptor. 5-HT-dependent chloride conductances have also been identified at the Retzius P-cell synapse of medicinal leeches (Lessmann and Dietzel, 1995) and are postulated to play a role in limiting presynaptic stimulation. Whether the 5-HT-dependent inhibition of egg laying has an adaptive role for $C$. elegans remains unknown; however, in $C$. elegans, environmental cues can cause inhibition of egg laying. Animals decrease egg laying in the absence of food, in a liquid environment, or during mechanical stimulation (Trent et al., 1983; Chalfie et al., 1985).

The inhibitory response to 5-HT on egg laying in ser- 1 mutant animals is attenuated after long-term exposure to serotonin. Wild-type animals can also decrease the response to the stimulatory effects of serotonin and nicotine after chronic exposure to these compounds (Schafer and Kenyon, 1995; Waggoner et al., 2000). Adaptation to chronic elevations in neurotransmitter concentration often occurs by downregulation of either receptors or downstream pathways. One possibility is that the MOD-1 receptor is downregulated in response to sustained elevations of 5-HT. In $C$. elegans, adaptation to nicotine involves a reduction in acetylcholine receptor levels in muscle, which requires TPA-1, a protein kinase C homolog (Waggoner et al., 2000).
We identified a withdrawal response of egg-laying behavior that occurs after removal from long-term 5-HT exposure. The development of a physical dependence is also seen with chronic drug use. For example, withdrawal effects are seen with many drugs of abuse, including cocaine, which causes increases in levels of monoamines such as serotonin at synapses. Withdrawal from cocaine has been shown to result in changes of levels of G-proteins and activators of G-protein signaling (Carrasco et al., 2003; Bowers et al., 2004; Carrasco et al., 2004). These initial results suggest that $C$. elegans may be a useful model system to study mechanisms of withdrawal responses.

5-HT produces stimulatory or inhibitory effects on behavior in C. elegans depending on the type of receptor present in the particular neural circuit controlling behavior. In other invertebrates, 5-HT has been shown to potentiate the frequency and amplitude of muscle contractions (Weiss et al., 1978; Lange, 2004), which can occur through calcium influx from the activation of voltage-gated L-type calcium channels (Brezina et al., 1994). This serotonergic pathway appears to be conserved in $C$. elegans. 5-HT has been shown to stimulate increases in the frequency of calcium transients in C. elegans vulval muscle, which requires EGL-19, the $C$. elegans homolog of the voltage-gated L-type calcium channel (Shyn et al., 2003). Genetic evidence also suggests that the EGL-19 channel is regulated by serotonergic pathways. Double mutants of egl-19 and either bas-1 or cat-4 (both 5-HT-deficient mutants) display more severe defects in egg laying than the egl-19 mutant alone (Waggoner et al., 1998). SER-1 appears to function like a $5-\mathrm{HT}_{2}$ receptor in the muscles that mediate the stimulatory effects of 5-HT on egg laying.

5 -HT is not the only transmitter within the egg-laying system that can produce both stimulatory and inhibitory effects on egg laying. Increasing synaptic levels of acetylcholine at the synapse through inhibition of acetylcholinesterase by aldicarb administration results in an inhibition of egg laying, whereas addition of cholinergic agonists such as levamisole results in stimulation of egg laying (Bany et al., 2003). For both acetylcholine and 5-HT, the stimulation of egg laying occurs via receptors expressed in the muscles while the inhibition occurs via receptors expressed in neurons.

We demonstrated that ser-1 mutant males show resistance to 5-HT-induced ventral tail curling normally seen in wild-type males placed in liquid containing exogenous 5-HT (Loer and Kenyon, 1993). ser-1 mutant males also exhibit defects in the turning step of mating behavior but are normal for mating efficiency at least in laboratory conditions. mod-1 appears to have a weaker but similar effect on male tail curling as ser-1. This result is different from its role in egg laying in which mod-1 produces an inhibitory effect on egg laying that opposes the stimulatory effect of ser-1. One possibility is that mod-1 functions in neurons to inhibit the activation of neurons required for ventral tail contraction. mod-1 mutant males, however, do not demonstrate corresponding defects in turning behavior like ser-1 mutant males, but like ser-1 mutant males, the mod-1 mutant males mate normally. ser-1;mod-1 males produce more severe turning defects than those seen in ser-1 males suggesting a contributing, but not essential, role for mod-1 in the male turning behavior. We observe mod-1::gfp expression in processes associated with sensory ray 4 (data not shown), supporting a possible role in mating behavior.

5-HT-defective mutants cat- 1, cat- 4 , and tph-1 can mate but with less efficiency than wild type (Hodgkin, 1983) (Fig. 5D), suggesting that there may be other serotonergic pathways involved in male mating. Processes associated with male tail sensory rays 1, 3, and 9 show 5 -HT immunoreactivity (Loer and 
Kenyon, 1993), and rays 7-9 mediate the timing of turning (Liu and Sternberg, 1995), suggesting that 5-HT could affect mating through these sensory pathways as well. This may explain the more severe defects in mating associated with 5-HT-defective mutants but not ser-1, mod-1, or mod-1;ser-1 mutant males. Abnormal synthesis of 5-HT may also result in behavioral abnormalities that indirectly disrupt mating efficiency. For example, it has been reported that cat-4 and tph-1 mutant animals move more slowly than wild-type animals (Hardaker et al., 2001; Cronin et al., 2005).

In mammals, $5-\mathrm{HT}_{2}$ receptors are important in the modulation of many behaviors (food intake, aggression, mood, sleep, and sex drive). Disruption of $5-\mathrm{HT}_{2}$ receptor function is associated with neurobehavioral abnormalities such as altered appetitive behavior, seizures, and drug dependency and can potentiate the response to antidepressant medication (Tecott et al., 1995; Rocha et al., 2002; Cremers et al., 2004). Chronic exposure to antidepressants and atypical antipsychotics, which bind $5-\mathrm{HT}_{2}$ receptors, directly result in decreases in receptor levels (Peroutka and Snyder, 1980; Andree et al., 1986; Willins et al., 1999). Such adaptive changes to these drugs may relate to the adaptive responses observed in C. elegans after chronic 5-HT receptor activation. Additional studies of the SER-1 receptor and serotonergic function in C. elegans may contribute to our understanding of $5-\mathrm{HT}_{2}$ receptors and their regulation in mammalian systems.

\section{References}

Andree TH, Mikuni M, Tong CY, Koenig JI, Meltzer HY (1986) Differential effect of subchronic treatment with various neuroleptic agents on seroto$\operatorname{nin}_{2}$ receptors in rat cerebral cortex. J Neurochem 46:191-197.

Bany IA, Dong MQ, Koelle MR (2003) Genetic and cellular basis for acetylcholine inhibition of Caenorhabditis elegans egg-laying behavior. J Neurosci 23:8060-8069.

Baran R, Aronoff R, Garriga G (1999) The C. elegans homeodomain gene unc- 42 regulates chemosensory and glutamate receptor expression. Development 126:2241-2251.

Bargmann CI (1998) Neurobiology of the Caenorhabditis elegans genome. Science 282:2028-2033.

Bastiani CA, Gharib S, Simon MI, Sternberg PW (2003) Caenorhabditis elegans Galphaq regulates egg-laying behavior via a PLC $\beta$-independent and serotonin-dependent signaling pathway and likely functions both in the nervous system and in muscle. Genetics 165:1805-1822.

Bowers MS, McFarland K, Lake RW, Peterson YK, Lapish CC, Gregory ML, Lanier SM, Kalivas PW (2004) Activator of G protein signaling 3: a gatekeeper of cocaine sensitization and drug seeking. Neuron 42:269-281.

Brenner S (1974) The genetics of Caenorhabditis elegans. Genetics 77:71-94.

Brezina V, Evans CG, Weiss KR (1994) Enhancement of Ca current in the accessory radula closer muscle of Aplysia californica by neuromodulators that potentiate its contractions. J Neurosci 14:4393-4411.

Brundage L, Avery L, Katz A, Kim UJ, Mendel JE, Sternberg PW, Simon MI (1996) Mutations in a C. elegans $\mathrm{G}_{\mathrm{q}} \alpha$ gene disrupt movement, egg laying, and viability. Neuron 16:999-1009.

Carrasco GA, Zhang Y, Damjanoska KJ, D'Souza DN, Garcia F, Battaglia G, Muma NA, Van de Kar LD (2003) A region-specific increase in Galphaq and Galpha11 proteins in brains of rats during cocaine withdrawal. J Pharmacol Exp Ther 307:1012-1019.

Carrasco GA, Damjanoska KJ, D’Souza DN, Zhang Y, Garcia F, Battaglia G, Muma NA, Van de Kar LD (2004) Short-term cocaine treatment causes neuroadaptive changes in Galphaq and Galpha11 proteins in rats undergoing withdrawal. J Pharmacol Exp Ther 311:349-355.

Chalfie M, Sulston JE, White JG, Southgate E, Thomson JN, Brenner S (1985) The neural circuit for touch sensitivity in Caenorhabditis elegans. J Neurosci 5:956-964.

Chalfie M, Tu Y, Euskirchen G, Ward WW, Prasher DC (1994) Green fluorescent protein as a marker for gene expression. Science 263:802-805.

Chase DL, Pepper JS, Koelle MR (2004) Mechanism of extrasynaptic dopamine signaling in Caenorhabditis elegans. Nat Neurosci 7:1096-1103.

Cremers TI, Giorgetti M, Bosker FJ, Hogg S, Arnt J, Mork A, Honig G, Bogeso KP, Westerink BH, den Boer H, Wikstrom HV, Tecott LH (2004) Inac- tivation of 5-HT(2C) receptors potentiates consequences of serotonin reuptake blockade. Neuropsychopharmacology 29:1782-1789.

Cronin CJ, Mendel JE, Mukhtar S, Kim YM, Stirbl RC, Bruck J, Sternberg PW (2005) An automated system for measuring parameters of nematode sinusoidal movement. BMC Genet 6:5.

Dempsey CM, Mackenzie SM, Gargus A, Blanco G, Sze JY (2005) Serotonin (5HT), fluoxetine, imipramine and dopamine target distinct $5 \mathrm{HT}$ receptor signaling to modulate Caenorhabditis elegans egg-laying behavior. Genetics 169:1425-1436.

Desai C, Horvitz HR (1989) Caenorhabditis elegans mutants defective in the functioning of the motor neurons responsible for egg laying. Genetics 121:703-721.

Desai C, Garriga G, McIntire SL, Horvitz HR (1988) A genetic pathway for the development of the Caenorhabditis elegans HSN motor neurons. Nature 336:638-646.

Duerr JS, Frisby DL, Gaskin J, Duke A, Asermely K, Huddleston D, Eiden LE, Rand JB (1999) The cat-1 gene of Caenorhabditis elegans encodes a vesicular monoamine transporter required for specific monoaminedependent behaviors. J Neurosci 19:72-84.

Fire A, Xu S, Montgomery MK, Kostas SA, Driver SE, Mello CC (1998) Potent and specific genetic interference by double-stranded RNA in Caenorhabditis elegans. Nature 391:806-811.

Giorgetti M, Tecott LH (2004) Contributions of 5-HT(2C) receptors to multiple actions of central serotonin systems. Eur J Pharmacol 488:1-9.

Hamdan FF, Ungrin MD, Abramovitz M, Ribeiro P (1999) Characterization of a novel serotonin receptor from Caenorhabditis elegans: cloning and expression of two splice variants. J Neurochem 72:1372-1383.

Hardaker LA, Singer E, Kerr R, Zhou G, Schafer WR (2001) Serotonin modulates locomotory behavior and coordinates egg-laying and movement in Caenorhabditis elegans. J Neurobiol 49:303-313.

Hobert O (2002) PCR fusion-based approach to create reporter gene constructs for expression analysis in transgenic C. elegans. Biotechniques 32:728-730.

Hobson RJ, Geng J, Gray AD, Kommuniecki RW (2003) SER-7b a constitutively active $\mathrm{G} \alpha_{\mathrm{s}}$ coupled $5-\mathrm{HT}_{7}$-like receptor expressed in the Caenorhabditis elegans M4 pharyngeal motorneuron. J Neurochem 10:22-29.

Hodgkin J (1983) Male phenotypes and mating efficiency in Caenorhabditis elegans. Genetics 103:43-64.

Horvitz HR, Chalfie M, Trent C, Sulston JE, Evans PD (1982) Serotonin and octopamine in the nematode Caenorhabditis elegans. Science 216:1012-1014.

Kamath RS, Ahringer J (2003) Genome-wide RNAi screening in Caenorhabditis elegans. Methods 30:313-321.

Lange $\mathrm{AB}$ (2004) A neurohormonal role for serotonin in the control of locust oviducts. Arch Insect Biochem Physiol 56:179-190.

Lessmann V, Dietzel ID (1995) Two kinetically distinct 5-hydroxytryptamineactivated $\mathrm{Cl}$ - conductances at Retzius P-cell synapses of the medicinal leech. J Neurosci 15:1496-1505.

Liu KS, Sternberg PW (1995) Sensory regulation of male mating behavior in Caenorhabditis elegans. Neuron 14:79-89.

Loer CM, Kenyon CJ (1993) Serotonin-deficient mutants and male mating behavior in the nematode Caenorhabditis elegans. J Neurosci 13:5407-5417.

Mello C, Fire A (1995) DNA transformation. Methods Cell Biol 48:451-482.

Mendel JE, Korswagen HC, Liu KS, Hajdu-Cronin YM, Simon MI, Plasterk RH, Sternberg PW (1995) Participation of the protein Go in multiple aspects of behavior in C. elegans. Science 267:1652-1655.

Miyabayashi T, Palfreyman MT, Sluder AE, Slack F, Sengupta P (1999) Expression and function of members of a divergent nuclear receptor family in Caenorhabditis elegans. Dev Biol 215:314-331.

Montgomery MK, Fire A (1998) Double-stranded RNA as a mediator in sequence-specific genetic silencing and co-suppression. Trends Genet 14:255-258.

Moresco JJ, Koelle MR (2004) Activation of EGL-47, a G $\alpha_{\mathrm{o}}$-coupled receptor, inhibits function of hermaphrodite-specific motor neurons to regulate Caenorhabditis elegans egg-laying behavior. J Neurosci 24:8522-8530.

Nurrish S, Segalat L, Kaplan JM (1999) Serotonin inhibition of synaptic transmission: $\mathrm{G} \alpha_{0}$ decreases the abundance of $\mathrm{UNC}-13$ at release sites. Neuron 24:231-242.

Okkema PG, Harrison SW, Plunger V, Aryana A, Fire A (1993) Sequence requirements for myosin gene expression and regulation in Caenorhabditis elegans. Genetics 135:385-404.

Olde B, McCombie WR (1997) Molecular cloning and functional expression of a serotonin receptor from Caenorhabditis elegans. J Mol Neurosci 8:53-62. 
Peroutka SJ, Snyder SH (1980) Regulation of serotonin2 (5-HT2) receptors labeled with $[3 \mathrm{H}]$ spiroperidol by chronic treatment with the antidepressant amitriptyline. J Pharmacol Exp Ther 215:582-587.

Rand JB, Nonet ML (1997) Neurotransmitter assignments for specific neurons. Cold Spring Harbor, NY: Cold Spring Harbor Laboratory.

Ranganathan R, Cannon SC, Horvitz HR (2000) MOD-1 is a serotoningated chloride channel that modulates locomotory behaviour in C. elegans. Nature 408:470-475.

Rocha BA, Goulding EH, O’Dell LE, Mead AN, Coufal NG, Parsons LH, Tecott LH (2002) Enhanced locomotor, reinforcing, and neurochemical effects of cocaine in serotonin 5-hydroxytryptamine $2 \mathrm{C}$ receptor mutant mice. J Neurosci 22:10039-10045.

Roth BL, Willins DL, Kristiansen K, Kroeze WK (1998) 5-Hydroxytryptamine2family receptors (5-hydroxytryptamine2A, 5-hydroxytryptamine2B, 5-hydroxytryptamine2C): where structure meets function. Pharmacol Ther 79:231-257.

Sawin ER, Ranganathan R, Horvitz HR (2000) C. elegans locomotory rate is modulated by the environment through a dopaminergic pathway and by experience through a serotonergic pathway. Neuron 26:619-631.

Schafer WR, Kenyon CJ (1995) A calcium-channel homologue required for adaptation to dopamine and serotonin in Caenorhabditis elegans. Nature 375:73-78.

Segalat L, Elkes DA, Kaplan JM (1995) Modulation of serotonin-controlled behaviors by Go in Caenorhabditis elegans. Science 267:1648-1651.

Shyn SI, Kerr R, Schafer WR (2003) Serotonin and Go modulate functional states of neurons and muscles controlling C. elegans egg-laying behavior. Curr Biol 13:1910-1915.

Sulston J, Dew M, Brenner S (1975) Dopaminergic neurons in the nematode Caenorhabditis elegans. J Comp Neurol 163:215-226.

Sulston JE, Horvitz HR (1977) Post-embryonic cell lineages of the nematode, Caenorhabditis elegans. Dev Biol 56:110-156.

Suo S, Sasagawa N, Ishiura S (2002) Identification of a dopamine receptor from Caenorhabditis elegans. Neurosci Lett 319:13-16.

Sze JY, Victor M, Loer C, Shi Y, Ruvkun G (2000) Food and metabolic signalling defects in a Caenorhabditis elegans serotonin-synthesis mutant. Nature 403:560-564.

Tecott LH, Sun LM, Akana SF, Strack AM, Lowenstein DH, Dallman MF, Julius D (1995) Eating disorder and epilepsy in mice lacking 5-HT2c serotonin receptors. Nature 374:542-546.
Trent C, Tsuing N, Horvitz HR (1983) Egg-laying defective mutants of the nematode Caenorhabditis elegans. Genetics 104:619-647.

Tsalik EL, Niacaris T, Wenick AS, Pau K, Avery L, Hobert O (2003) LIM homeobox gene-dependent expression of biogenic amine receptors in restricted regions of the C. elegans nervous system. Dev Biol 263:81-102.

Waggoner LE, Zhou GT, Schafer RW, Schafer WR (1998) Control of alternative behavioral states by serotonin in Caenorhabditis elegans. Neuron 21:203-214.

Waggoner LE, Dickinson KA, Poole DS, Tabuse Y, Miwa J, Schafer WR (2000) Long-term nicotine adaptation in Caenorhabditis elegans involves PKC-dependent changes in nicotinic receptor abundance. J Neurosci 20:8802-8811.

Weinshenker D, Garriga G, Thomas JH (1995) Genetic and pharmacological analysis of neurotransmitters controlling egg laying in C. elegans. J Neurosci 15:6975-6985.

Weiss KR, Cohen JL, Kupfermann I (1978) Modulatory control of buccal musculature by a serotonergic neuron (metacerebral cell) in Aplysia. J Neurophysiol 41:181-203.

Wenick AS, Hobert O (2004) Genomic cis-regulatory architecture and trans-acting regulators of a single interneuron-specific gene battery in $C$. elegans. Dev Cell 6:757-770.

White J (1988) The anatomy. In: The nematode Caenorhabditis elegans (Wood W, ed), pp 81-121. Cold Spring Harbor, NY: Cold Spring Harbor Laboratory.

White JG, Southgate E, Thomson JN, Brenner S (1976) The structure of the ventral nerve cord of Caenorhabditis elegans. Philos Trans R Soc Lond B Biol Sci 275:327-348.

White JG, Southgate E, Thomson JN, Brenner S (1986) The structure of the nervous system of the nematode Caenorhabditis elegans. Philos Trans R Soc Lond B Biol Sci 314:1-340.

Wightman B, Baran R, Garriga G (1997) Genes that guide growth cones along the C. elegans ventral nerve cord. Development 124:2571-2580.

Willins DL, Berry SA, Alsayegh L, Backstrom JR, Sanders-Bush E, Friedman L, Roth BL (1999) Clozapine and other 5-hydroxytryptamine-2A receptor antagonists alter the subcellular distribution of 5-hydroxytryptamine-2A receptors in vitro and in vivo. Neuroscience 91:599-606. 